Morland (1967) had a twofold consumption in their patients with myocardial infarction, and a level almost as high as this in those with peripheral artery disease. Our results, as presented here, do not rule out the findings of Paul et al. (1968) that I.H.D. patients may have a slightly higher consumption of sucrose (not statistically significant) than controls.

As Paul et al. (1968) point out, Yudkin and Roddy's observations were made after clinical recognition of atherosclerotic disease, and on a group selected by survival. Nevertheless, using Yudkin's questionary we have been unable to reproduce his results in spite of considerable manipulation of the I.H.D. group.

The inclusion in the I.H.D. group of patients diagnosed on the findings of E.C.G. abnormalities may be open to criticism, but though not all of these patients will necessarily come to frank clinical I.H.D., the incidence of I.H.D. will certainly be far higher than in a comparable group with normal E.C.G. readings. The Framingham study (Kagan, Dawber, Kannel, and Revotskie, 1962) has shown that an E.C.G. abnormality is among the high-risk factors. Morris, Kagan, Pattison, Gardner, and Raffle (1966) have found S-T/T wave abnormality to be an important I.H.D. precursor. If Yudkin's hypothesis be valid, one would expect that sugar intake in this group diagnosed by E.C.G. would be manifestly higher than in the control group, though not at the twofold level indicated by Yudkin and Roddy. In practice this was not so. The tables using the complete I.H.D. group also have the advantage, mentioned by Paul et al. (1968), of not being entirely selected survivors. On the other hand, data collected far in advance of first coronary attack-as were the data of Paul et al. (1968)may also prove defective.
One interesting observation was that there was no correlation between total sugar intake and serum cholesterol level in either the I.H.D. or the control group. There was no correlation between sugar intake and weight gain after the age of 25 , so that clearly other dietary factors in addition to sugar intake are relevant to the problems of obesity.

These current results suggest that considerably more confirmation in man is required before Yudkin's hypothesis can be accepted.

We are glad to acknowledge our indebtedness to the other members of the survey team-Drs. J. C. Evans, A. M. Leach, and G. B. Schofield, and their staffs at Harwell, Springfields, and Windscale respectively.

\section{REFERENCES}

Crown, S., Duncan, K. P., and Howell, R. W. (1969), British fournal of Psychiatry. In press.

Dalderup, L. M., Doornbos, R., and De Vries, J. E. (1968). Lancet, 1, 819.

Gertler, M. M. White, P. D., Cady, L. D., and Whiter, H. H. (1964). American fournal of the Medical Sciences, 248, 377.

Howell, R. W. (1966). Lancet, 1, 1033 .

Kagan, A., Dawber, T. R., Kannel, W. B., and Revotskie, N. (1962). Federation Proceedings, 21, No. 4, Part 2, p. 52

Morris, J. N., Kagan, A., Pattison, D. C., Gardner, M. J., and Raffle, P. A. B. (1966). Lancet, 2, 553.

Paul, O., et al. (1963). Circulation, 28, 20.

Paul, O., MacMillan, A., McKean, H., and Park, H. (1968). Lancet, 2, 1049.

Yudkin, J. (1957). Lancet, 2, 155.

Yudkin, J. (1964). Lancet, 2, 4.

Yudkin, J. (1966). Lancet, 1, 930.

Yudkin, J., and Morland, J. (1967). American fournal of Clinical Nutrition, $20,503$.

Yudkin, J., and Roddy, J. (1964). Lancet, 2, 6.

\title{
"Normal Central Venous Pressure," Significance of Reference Point and Normal Range
}

\author{
FELIX DEBRUNNER,* M.D. ; FRITZ BÜHLER, † M.D.
}

\begin{abstract}
Cummary : The principal methods for determining the central venous pressure have been compared in 26 patients undergoing cardiac catheterization. The method in which the reference point is taken to be $10 \mathrm{~cm}$. above the surface supporting a horizontal patient gave false high-pressure values. All the other methods, however, gave pressure values which corresponded to those obtained in the catheter studies.
\end{abstract}

\section{Introduction}

The technically simple determination of central venous pressure has become a standard procedure in the intensive care unit. The central venous pressure provides a dynamic index of the effective circulation blood volume in relation to the efficiency of the right ventricle. The pressure in the superior vena cava is virtually identical with the mean pressure in the right atrium (Richards et al., 1942). The normal ranges in the first papers reporting central venous pressure measurements vary from author to author-for example, Richards et al. (1942) and Wood (1956). Recent studies agree that the normal range is about $8 \mathrm{~cm}$. of water-for example, Weil et al. (1965), Burri

\section{* Chief Resident.}

t Resident.

Department of Internal Medicine, University of Basle, Switzerland. and Allgöwer (1967), and Hardaway (1968). On the other hand, there is a complete lack of uniformity regarding the choice of the extrathoracic reference point.

In a large number of patients selected at random we measured the central venous pressure with the aid of the various methods -that is, using the various reference points-and noted that the central venous pressure value in one and the same patient varied, depending on the method used. In some cases, in fact, the values noted lay outside the normal range from the given method. If the various techniques record the same value they should yield equivalent results. As this is not the case the discrepancies noted must be due to the type of technique used. The aim of our study was to prove this point.

Our findings confirm that this hypothesis holds in six of the seven methods studied. We noticed to our surprise, however, that the remaining method, a widely used technique, deviates markedly in this respect.

\section{Method}

Twenty-six patients (18 men, 8 women) aged 39 to 79 years, with an average age of 63 , who had catheters placed in the superior vena cava directly above the right atrium, were followed by means of lateral thoracic $x$-ray films. The patients were placed horizontally on a firm surface. With the aid of a 
slide gauge and spirit-level, the thoracic anteroposterior diameter was determined perpendicular to the firm surface from a point midway between the sternal jugulum and xiphoid process. The anteroposterior diameter at the same point was also determined with a chest $x$-ray film. The focus-film distance was $150 \mathrm{~cm}$. The focus-object distance (focus to the median of the patient) was $125 \mathrm{~cm}$. The magnification factor was thus $1 \cdot 2$ (Poppe, 1961). The position of the catheter was defined as the line passing through the tip of the catheter parallel to the surface supporting the patient. The reference points of the various techniques were drawn on the $x$-ray film and the deviation from the tip of the catheter was measured. Ventral deviations were regarded as positive and dorsal deviations as negative. The significance of the results was determined by using the $t$ test. The pressure values were not considered, since this criterion was not of any immediate interest and also because the abnormal central venous pressure present in certain cases would have prevented the results from being uniform. For this reason it was also impossible to determine a normal range.

\section{Results}

The radiologically measured difference between the tip of the catheter and the reference points used in the various methods is shown in Table I. The difference between the tip of the catheter and the reference points used by Cournand et al. (1943) $(6.6 \mathrm{~cm}$. dorsal from the angle of Louis) and by Burri and Allgöwer (1967) (three-fifths of the thoracic diameter as measured from the supporting surface) are not significant $(P=0 \cdot 10-0 \cdot 20)$. The reference points of the other methods differ significantly $(P<0.001)$.

TABLB I.-Reference Point and Catheter Position in 26 Patients. The Point of the Catheter is Considered to be Zero. Dorsal Deviation is Reint of the Carterer is Considered to be Zero. Dorsal Deviation is Regarded as Negative, Ventral Deviation as Positive. The Actual Distance was Derived from the Radiologicaly Measured Distance,
Using the Magnification Factor

\begin{tabular}{|c|c|c|}
\hline $\begin{array}{c}\text { Reference } \\
\text { Point }\end{array}$ & $\begin{array}{l}\text { Radiologically } \\
\text { Measured Distance } \\
\text { from Catheter } \\
\text { in cm. }\end{array}$ & $\begin{array}{l}\text { Actual Distance } \\
\text { from Catheter } \\
\text { in cm. }\end{array}$ \\
\hline $\begin{array}{l}10 \mathrm{~cm} \text {. ventral from dorsal surface } \\
\mathrm{cm} \text {. dorsal from angle of Louis } \\
.6 \mathrm{~cm} \text {. dorsal from angle of Louis } \ldots \\
\text { angle of Louis } \ldots \\
\text { thoracic diameter } \ldots\end{array}$ & $\begin{array}{l}-4.06 \pm 1.59 \\
+2.05 \pm 1.37 \\
+0.14 \pm 0.44 \\
+7.94 \pm 1.45 \\
-3.00 \pm 1.30 \\
-0.42 \pm 1.34\end{array}$ & $\begin{array}{l}-3.38 \\
+1 \cdot 71 \\
+0.11 \\
+6.62 \\
-2.50 \\
-0.35\end{array}$ \\
\hline
\end{tabular}

The distance between the tip of the catheter (situated between the superior vena cava and right atrium) and the supporting surface averaged $13.3 \mathrm{~cm}$. In the $x$-ray pictures this distance corresponded to $16 \mathrm{~cm}$. (S.D. 0.05).

The thoracic diameter measured $21.6 \mathrm{~cm}$. (S.D. 2.7). Radiologically this measurement averaged $25.9 \mathrm{~cm}$. The magnification factor was thus $1 \cdot 2$ (S.D. 0.06), which corresponds to the theoretical value.

\section{Discussion}

The reference points of the various techniques are situated at various levels along the anteroposterior thoracic diameter and are in each case regarded as the zero point of the given system of measurement. The pressure values vary greatly, depending on the method used, and cannot be compared with one another. For obvious reasons these discrepancies are due to the different reference points used. The latter are selected on the basis of two different principles. In one case the aim is to select an easily detectable extrathoracic point with a constant anatomical relationship to the right atrium-for example, Wood (1956) and Jaikaran and Sagay (1968). In the second case the extrathoracic reference point is taken to lie at the same height as the right atrium-for example, Moritz and von Tabora (1910), Lyons et al. (1938), Richards et al. (1942), Guyton and Greganti (1956), Weil et al. (1965), Burri et al. (1966), and Hardaway (1968). The commonest methods are listed in Table II.
TABLE II.-Definition of the Reference Points and Corresponding Normal Ranges

\begin{tabular}{|c|c|c|c|}
\hline Author & $\begin{array}{l}\text { Definition of Reference } \\
\quad \text { Points }\end{array}$ & $\begin{array}{l}\text { Normal } \\
\text { Range in } \\
\mathrm{cm} \text {. of } \\
\text { Water }\end{array}$ & $\begin{array}{l}\text { Limits } \\
\text { in } \\
\text { cm. of } \\
\text { Water }\end{array}$ \\
\hline Moritz and von Tabora & $5 \mathrm{~cm}$. ventral from sternal inser- & - & - \\
\hline $\begin{array}{l}\text { Lyons et al. (1938) } \\
\text { Richards et al. (1942) } \\
\text { Cournand et al. (1943) }\end{array}$ & $\begin{array}{l}10 \mathrm{~cm} \text {. ventral from dorsal surface } \\
5 \mathrm{~cm} \text {. dorsal from angle of Louis } \\
6.6 \mathrm{~cm} \text {. dorsal from angle of Louis }\end{array}$ & $\stackrel{(8) *}{5 \cdot 3}$ & $\begin{array}{l}(0 \text { to } 8) \\
0.8 \text { to } 6.1\end{array}$ \\
\hline $\begin{array}{l}\text { Wood (1956) } \\
\text { Jaikaran and Sagay }\end{array}$ & Angle of Louis & $\begin{array}{l}7 \\
7\end{array}$ & $\begin{array}{l}-5 \text { to } 2 \\
-4 \text { to } 3\end{array}$ \\
\hline Weil et al. (1965) & $\frac{1}{2}$ thoracic diameter & $\begin{array}{l}7 \\
6\end{array}$ & $\begin{array}{l}3 \text { to } 10 \\
6 \text { to } 12\end{array}$ \\
\hline $\begin{array}{l}\text { Burri and Allgöwer } \\
\text { (1967) }\end{array}$ & $\begin{array}{l}3 / 5 \text { thoracic diameter measured } \\
\text { from dorsal surface }\end{array}$ & 7 & 3 to 10 \\
\hline
\end{tabular}

* Normal range and limits subsequently used in central venous pressure measurements based on the zero point in Lyons's method.

Basing their work on 56 radiological or post-mortem examina- $\vec{\circ}$ tions, Lyons et al. (1938) calculated that with the patient in a $\vec{\omega}$ horizontal position the level of the right atrium was $10 \mathrm{~cm}$. $)$ above the supporting surface. Lyons et al. used this point as the zero point for the determination of the peripheral venous pressure. Later this reference point won widespread acceptance ir in cardiology as a means of determining the central venous o pressure (Mendel, 1968), values of 0 to $8 \mathrm{~cm}$. of water (corresponding roughly to 0 to $6 \mathrm{~mm}$. $\mathrm{Hg}$ ) being generally regarded $\overrightarrow{\vec{P}}$ as normal.

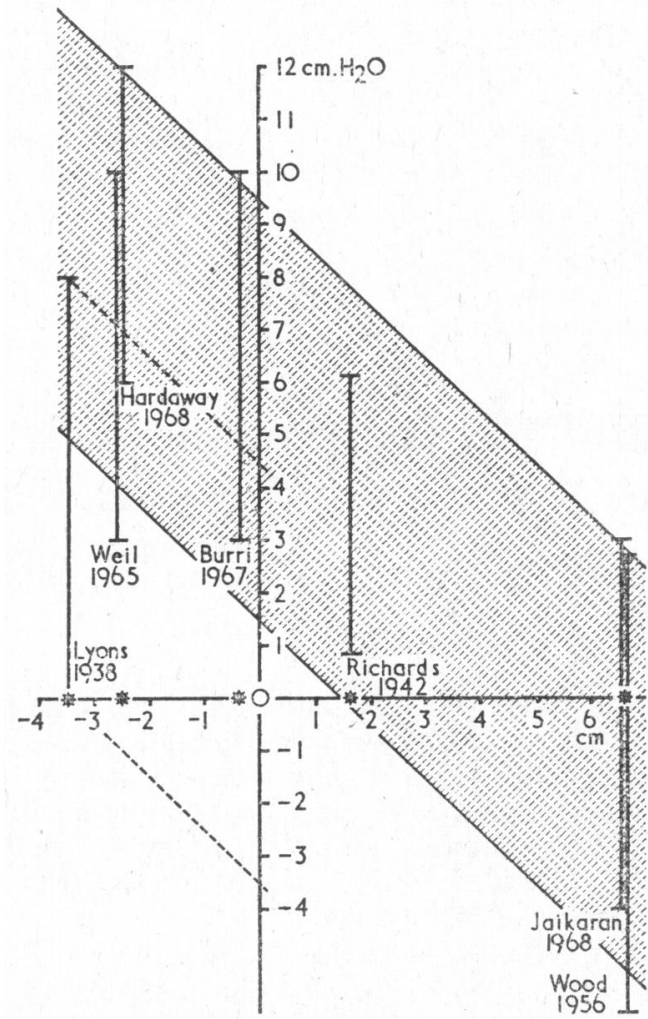

Comparison of the principal methods for determining central venous pressure. The distances of the various reference points (stars) from the tip of the catheter (Table I) are plotted against their corresponding ranges. Corresponding pressure values of the different methods lie on a line running paralle to a line bisecting the angle formed by the abscissa and the ordinate. Ventral deviations from the tip of the catheter (zero point) are positive, dorsal deviations neontive. The hatched field showsal deviawith a height of $8 \mathrm{~cm}$ of water in which all but of the methods (Table II) roughly agree.

If the physical principle of communicating tubes is borne in mind there must be, for equivalent techniques, a simple linear $\frac{0}{2}$ correlation between measured central venous pressures and the ? distance of the reference point from the tip of the catheter. In the Graph we have plotted these distances (see Table I) against the corresponding normal ranges (see Table II). It will be seen 
from this graph that the corresponding pressure values lie on a line running parallel to a line bisecting the angle formed by the abscissa and the ordinate. All but one of the methods listed in Table II agree within a normal range of about $8 \mathrm{~cm}$. of water, in which connexion the upper limits are more uniform than the lower ones.

To this general measure of agreement between the various methods there is one exception, however, since the values obtained with the method described by Lyons et al. (1938) deviate widely from the findings of the other authors. As the Graph shows, when Lyons's reference point is used the limits should be 5 to $13 \mathrm{~cm}$. of water, and not the 0 to $8 \mathrm{~cm}$. generally employed. Moreover, the lower range-that is, 0 to $3 \mathrm{~cm}$. of water-lies below the tip of the catheter, which would correspond to a negative pressure in the right atrium. This has been contradicted by the results of Richards et al. (1942) and of Cournand et al. (1943), who found a positive mean pressure in the right atrium. False high values for right atrial pressure and right ventricular telediastolic pressure may lead to an erroneous diagnosis of right ventricular failure. In the management of shock false high values may cause the effective blood volume to be overestimated.

\section{Conclusions}

Appraisal of the various reference points and normal ranges used in the determination of the central venous pressure has shown the following:

As shown in our comparative study, after appropriate correction as regards the deviation of the zero point from the tip of the catheter, six of the seven methods investigated agree with one another. A range of $8 \mathrm{~cm}$. of water is considered normal.
The method in which the reference point is taken to be $10 \mathrm{~cm}$. above the surface supporting a horizontal patient yields false high values if the generally used range $(0$ to 8 $\mathrm{cm}$. of water) is adopted.

The selection of the reference point-the distinctive feature of these various methods-is of minor importance. The sole requirement in this respect is that it should be possible to determine the reference point both accurately and easily. Naturally, for purposes of comparison, it would be desirable if a uniform method could be agreed on. The corresponding pressure values yielded by the various methods can be read off from the Chart.

\section{REFERENCES}

Burri, C., and Allgöwer, M. (1967). Schweizerische medizinische Wochenschrift, 97, 1414.

Burri, C., Müller, W., Kuner, E., and Allgöwer, M. (1966). Schweizerische medizinische Wochenschrift, 96, 624

Cournand, A., et al. (1943). Surgery, 13,964.

Guyton, A. C., and Greganti, F. P. (1956). American fournal of Physio$\log y, 185,137$.

Hardaway, R. M. (1968). Clinical Management of Shock, p. 163. Springfield, Illinois, Thomas.

Jaikaran, S. M. N., and Sagay, E. (1968). British fournal of Surgery, 55,609

Lyons, R. H., Kennedy, J. A., and Burwell, C. S. (1938). American Heart fournal, 16, 675 .

Mendel, D. (1968). A Practice of Cardiac Catheterisation, p. 222. London, Blackwell Scientific Publications.

Moritz, F., and von Tabora, D. (1910). Deutsches Archiv für klinische Medizin, 98, 475 .

Poppe, H. (1961). Technik der Röntgendiagnostik, 2nd ed., p. 535. Stuttgart, Thieme.

Richards, D. W., Cournand, A., Darling, R. C., Gillespie, W. H., and Baldwin, E. F. (1942). American fournal of Physiology, 136, 115

Weil, M. H., Shubin, H., and Rosoff, L. (1965). Fournal of the American Medical Association, 192, 668.

Wood, P. H. (1956). Diseases of the Heart and Circulation, 2nd ed., p. 188. London, Eyre and Spottiswoode.

\title{
Oral Calcium-loading Test in Rickets and in Neonatal Tetany : Effect of Vitamin D
}

\author{
DAVID G. D. BARR,* M.B., M.R.C.P.ED., D.C.H. ; JOHN O. FORFAR, $†$ M.C., M.D., F.R.C.P.(LOND., ED.), D.C.H.
}

\begin{abstract}
Summary : In an oral calcium-loading test performed $N$ on 10 infants with vitamin-D deficiency rickets and low fasting calcium levels, a comparison of results before and after therapy showed that vitamin $D$ raised the serum calcium level at each stage of the test and altered the response so that a more rapid and substantial rise and fall in serum calcium occurred.

The effects of vitamin $D$ therapy on newborn infants with hypocalcaemic hyperphosphataemic tetany in another study suggests that these infants should be treated in this way to make them more responsive to oral calcium therapy.
\end{abstract}

\section{Introduction}

A calcium-loading test designed to measure the short-term effect of a standard dose of oral calcium on the serum calcium level was previously carried out in idiopathic hypercalcaemia and in a control group of normocalçaemic infants (Barr and Forfar, 1969). In the present study the test was applied to children suffering from vitamin-D-deficiency rickets with a tendency to hypocalcaemia and to infants with hypocalcaemic hyperphosphataemic tetany. The effect of therapeutic dosage of vitamin $\mathrm{D}$ in these two conditions was assessed.

* Senior Registrar, Royal Hospital for Sick Children, Edinburgh 9. † Professor of Child Life and Health, University of Edinburgh.

\section{Patients, Procedures, and Methods}

Of 10 infants with vitamin-D-deficiency rickets, ranging in age from 3 months to 2 years 9 months, five had simple nutritional rickets, two had rickets following extreme prematurity, two had coeliac rickets, and one had rickets after neonatal hepatitis. All these cases were confirmed radiologically and biochemically. None had vitamin-D-resistant rickets.

A control group, in which the normal response in 15 infants aged 2 months to 2 years 6 months had previously been defined (Barr and Forfar, 1969), formed a basis for comparison with the rachitic infants.

Seven patients, aged 6 to 14 days, with hypocalcaemic hyperphosphataemic tetany of the newborn were tested when serum calcium levels were low ; four, aged 13 to 19 days, and one, aged 7 weeks, while recovering on oral calcium supplements and five, aged 14 to 21 days, while recovering on oral calcium supplements together with large doses of vitamin $D$. The test procedure and methods have been previously described (Barr and Forfar, 1969).

\section{Results}

Control Group.-In the control group the mean values and range have been defined (Barr and Forfar, 1969). The normal 